These profound symptoms of poisoning from such minute doses have given rise to various explanations. The fact that the toxic power of arsenic varies largely according to the chemical form in which it is present, the arseniates, for instance, being barely half as poisonous as the arsenites, has led many to assume that the arsenic was present in the beer either as an arsene, or even in some more subtle biological form. The work of Gossio and others upon the power of the penicillium brevicaule to form highly poisonous gaseous substances from minute traces of solid arsenic compounds has been adduced by many in support of this hypothesis.

A further consideration of interest in this connection is the fact that arsenic must be considered, at any rate to some extent, a cumulative poison. The interesting and minute work of Gautier upon the excretion of arsenic under normal conditions by the skin, the hair and the menstrual fluid, and the storing of it in the thyroid gland, the thymus gland and the brain, are of especial interest. The recent researches of Sslowzow should also find mention here. This observer found that in animals poisoned with arsenic the arsenic was stored in the liver, and further, that it formed a compound with the nucleins, which showed itself to be resistant to the action of hydrochloric acid and pepsin, and that it was, in all probability, stored in this form in the cell nuclei. This work, so far as concerns the storing of arsenic in the liver and its excretion by the epidermal appendages, has been recently confirmed by Dixon Mann.

That arsenic is slowly excreted has been known for some time. E. Ludwig found arsenic in the urine of a dog forty days after the last dose had been ingested, Wood found it in the urine of patients eighty and ninety days after intoxication with arsenic.

Although arsenic may be in this sense cumulative, it does not follow that its poisonous action is cumulative. In fact, its forming an indigestible nuclein compound speaks against this. Further, we know from clinical experience, from the Styrian arsenic eaters, and from numerous pharmacological experiments on animals, that tolerance to arsenic is easily produced. Indeed, continued small doses of arsenic, so far from causing symptoms allied to those which occurred in the beer poisoning epidemic, as a rule improve nutrition and have a general tonic action.

If we pass from the consideration of the nature of the poison to the symptoms which occurred in the Manchester patients, we find many points of extreme interest. Speaking generally, the phenomena present corresponded more or less closely with the classical symptoms of arsenical poisoning. It must be remembered, however, that the discovery of selenium opens the whole question of arsenical poisoning afresh. So far as pharmacological experiments upon animals go, the only difference between the chronic poisonous action of these two substances is that tolerance to selenium is apparently never produced, and that this substance, in continued small doses, produces wasting by virtue of a specific stimulating action which it exerts upon the breaking down of the nitrogenous constituents of the tissues. Thus we must confess that the presence of selenium along with arsenic in the Manchester beer explains many otherwise anomalous symptoms.

It has long been known that excess of alcoholic beverages causes in the drinkers a disease known as peripheral neuritis. The rôle played by alcohol in this disease has heretofore been regarded as sufficiently important to justify the designation of alcoholic neuritis for this condition. It has, however, been observed that the drinkers of certain kinds of alcoholic beverages are much more prone to this affection than the drinkers of others, and further, that the strength of the beverage in alcohol seems to bear no proportion to its proneness to cause so-called alcoholic neuritis. Drinkers of distilled spirits and wines are much less liable to suffer from peripheral neuritis than beer and stout drinkers. These considerations have led many physicians to look upon this disease as caused by the beverage rather than by the alcohol $\left(\mathrm{C}_{2} \mathrm{H}_{5} \mathrm{OH}\right)$. Peripheral neuritis was a prominent symptom in the Manchester epidemic, and there can be little doubt it was caused by the arsenic and selenium compounds in the beer. Other metallic and organic poisons, such, for instance, as beri-beri, give rise to a similar condition. This epidemic has, therefore, very much increased the previous doubt concerning the part played by alcohol itself in the so-called alcoholic neuritis.

With regard to the lessons to be learnt from the recent beer-poisoning epidemic, the chief one certainly is to beware of mineral acids in the preparation of all foodstuffs. It is difficult to see how mineral acids, or at any rate acids (in this connection must be observed the difficulty of freeing an acid like tartaric acid from lead) can be dispensed with. They can, however, certainly be put on the market, from whatever source they may be obtained, pure. Although absolute chemical purity must be regarded as a dream of the fatuous ignoramus, there should be no difficulty in the sulphuric acid manufacturers providing an acid which one can term at least harmlessly impure. A further important result of the investigations attending this epidemic is the discovery of selenium in poisonous doses in a beverage actually consumed. This substance has no doubt slipped in and out of many previous arsenic epidemics, escaping observation, as it were, between the stools of chemistry and pharmacology. Now that we are awake to its poisonous existence, in the next arsenic epidemic, which we hope may be long deferred, we shall be able, no doubt, to work out the exact part it plays. It is interesting to note in this connection that it is an impurity of both brimstone and pyrites acid, and that it occurs along with tellurium in certain Japanese sulphurs which are free from arsenic.

\section{MUSICAL ARCS.}

WE have already described in a previous issue (NATURE, December 20, I900, p. 182) the discovery of a new musical instrument in the electric arc made by Mr. Duddell and communicated by him to the Institution of Electrical Engineers last December. The fame, if not the music, of Mr. Duddell's arc penetrated, it appears, to Vienna, where the experiments were repeated at the Technological Institute, and thence returned to the English lay Press. The Daily Mail of January 12 last contained an article on "Music in Flame," the result of an interview with Prof. Ayrton on the subject of Mr. Duddell's experiments, in the course of which he suggested that it might be possible to utilise the discovery for the purpose of public entertainment. Would it not be possible, for example, to play a tune upon the arc lamps used in lighting a hall, the musician being at a distance-even outside the building-and playing on the ingenious key-board devised by $\mathrm{Mr}$. Duddell? At the time this article appeared the prophecy may have seemed somewhat extravagant. Mr. Duddell's experiments were conducted, it will be remembered, by shunting an arc burning between solid carbons-the cored carbon arc has no music in its soul-by a circuit containing capacity and self-induction, and the note emitted by the arc was varied by altering the capacity or self-induction in the shunt circuit. The shunt circuit was, however, placed directly across the terminals of the arc, and there was no evidence of any possibility of playing tunes on the arc from any distance; and, further, the arc lamps used in the experiment were hand-fed and it was not unreasonable to suppose that the mechanism and magnet coils of an automatic arc lamp would effectually interfere with the music. 
Extravagant, however, as Prof. Ayrton's suggestion may have seemed, it appears from Mr. I)uddell's reply to the discussion on his paper (just published in the Jcurnal of the Institution of Electrical Engineers) that it is more than justified by the truth. During the time that Mr. Duddell was experimenting on the musical arc at the Central Technical College, Mr. Bradfield noticed that an arc with which he was experimenting in Sir W. de W. Abney's laboratory started playing tunes. About the same time also Sir Norman Lockyer noticed that the arc in his laboratory was behaving in an erratic manner, though he did not detect any definite tune. At the time neither Mr. Bradfield nor Sir Norman Lockyer were able to account for this strange behaviour, but on the publication of Mr. Duddell's paper the explanation became evident. All the arcs were being supplied from the street mains and the disturbances ivere due to the shunt circuit with which Mr. Duddell was working at the Central 'Technical College. The arcs at Sir W. Abney's and Sir Norman Lockyer's laboratories were thus able to detect and repeat the tunes Mr. Duddell was playing on his arc, although they were in no way adjusted to make them specially sensitive, and were only connected to $\mathrm{Mr}$. Duddell's arc by virtue of being on the same distributing network of supply mains. Sir. W. Abney's laboratory is on the opposite side of the road to the Central Technical College and at a distance of about 400 yards in a straight line, and at a much greater distance if measured along the street mains. Sir Norman Lockyer's laboratory is at about the same distance, on the same side of the road as the College.

If such remarkable results as these can be obtained without any design or arrangements of the circuit, who shall say what cannot be effected by a proper study of the best conditions and attention to the necessary details? Those who heard the music discoursed by the arcs at the Institution of Electrical Engineers will agree that some improvement is necessary before the arc can compete as a musical instrument with the violin or grand organ. But it is sufficiently demonstrated, we think, that Prof. Ayrton's prophecy is by no means excessive, and the time is perhaps not far distant when every central station will have its resident musician to play patriotic airs on the street arcs at the Coronation of the King and like occasions, and we shall be able to realise something of the grandeur of "the morning stars singing together."

\section{LITTLE'S EXPEDITION TO OMI AND THE TIBETAN BORDER.'}

HOLIDAY trip from Central China (Chung-King), through the red sandstone basin of western Sze Chuan to the granite frontiers of Tibet, and back again by the traditional water-highway of the Yangtse, is not an experience which falls within the reach of every mercantile explorer in the East; and it derives additional interest in Mr. Little's case from the fact that he was accompanied by his wife. The story of the expedition is told in the form of a diary, a form in which it is almost impossible to avoid a certain amount of monotonous reiteration of incident in the daily record of progress, and which is, perhaps, a little too official in its method for an ordinary traveller's tale; but it is interesting all through, and the deductions which Mr. Little draws from his observations afford valuable food for reflection to those who look to the opening up of China to western methods of economic development. From Chung King to Kia ting, the town which lies at the foot of the classical Omi (the Fusilama of western China), Mr. Little and his wife adopted the Chinese traditional mode of transport, which consists of a sedan chair carried on the shoulders

1 "Mount Omi and Beyond." By A. J. Little. Pp. xiv +272 . (London: W. Heinemann, $x$ gox.) NO. I 640, VOL. 63$]$ of coolies ; and it is a method which, in the present stage of Chinese social advancement, secures for a traveller as much respect and attention as a coach-and-four would in England. It at once lifts him morally and physically above the steaming crowds of humanity which, in a region which is free from the depleting processes of famine, swarm together in one great pitiless struggle for existence. The whole basin of the Yangtse to the foot of the western mountains presents the same aspect of overcrowded population. Every acre of available soil is cultivated, every yard of productive land is occupied. There is no room to pitch even the smallest of tents, and travellers have perforce to put up with the accommodation afforded by the indigenous hotel. It is the varied nature of the sort of entertainment which is found at these Chinese inns, with the everlasting accompaniment of personal unrestrained curiosity on the part of a people who look on all foreign devils (especially a feminine devil) as fair game for their inquisitiveness, which forms the leading feature in Mr. Little's account of his outward journey. The trip was made in 1897 , and it is worthy of remark (apropos of more recent events in China) that even then Mr. Little was able to discern a very considerable change for the worse in the attitude of the people towards strangers; and this change had taken place during the previous ten years. Fifteen years before Mr. Little's journey that delightful writer and traveller, Baber, had visited western Sze Chuan and Mount Omi, and his account of his travels certainly tends to confirm Mr. Little's view. that a growing antipathy to foreign incursions was gradually accumulating which would eventually tend to mischievous results. Our travellers were occasionally treated to something worse than the derisive jeers of the townspeople. "Clods of earth and cabbage-stalks" now and then followed the maledictions of the crowd. And yet there was much good-natured hospitality and courtesy frequently shown both by priests and people. How far the interference of missionaries with the old traditions of a form of Buddhism which seems to be of a far higher and purer type in western China than anything in Tibet, may have influenced the minds of the people is open to question. Mr. Little is evidently doubtful on the point. With every desire to give missionaries credit for their devoted spirit of enterprise, he seems to think that their efforts in the work of regeneration have not always been wisely directed.

Of the wonderful beauty of Mount Omi scenery, its temples and groves, its priests, its pilgrims and its precipices (from the summit of one of which the crowning "glory of Buddha" is to be seen), Mr. Little has much to say, and he-says it well. When the Chinese introduce railways more freely into their country, along with that "western knowledge and machinery" which is to give to them the "command of the industrial world," Omi (beloved of Baber and photographed by Mrs. Little) will be as much an object of western pilgrimage as of eastern.

Mr. Little makes the height of Omi to be 10,500 feet above sea, and Sai King Shan (a mountain which he subsequently visited), I I, 100. This exactly reverses the altitudes given by Baber, who makes Omi I I, IOO feetthe height which is preserved in Mr. Little's map. Hypsometrical determinations are proverbially unsatisfactory, especially when the observations are made under the influence of very varied "weather" conditions. Possibly, also, Mr. Little's results may be affected by the fact that he "boiled his thermometer" (he says he did so, repeatedly) instead of registering the temperature of the steain.

The Littles did not penetrate far into Tibet. Indeed, it depends on whether Ta chien lu (Dar chen do; botb names seem to be correct) is to be regarded as the frontier of Tibet, or whether the boundary is politically (as it is geographically) to be found in the Tung river. 